\title{
DỨcin
}

Technological University Dublin

ARROW@TU Dublin

\section{Sociology in the 21st Century: Reminiscence and Redefinition}

\author{
Rana Jawad \\ University of Bath, R.Jawad@bath.ac.uk \\ Paddy Dolan \\ Technological University Dublin, paddy.dolan@tudublin.ie \\ Tracey Skillington \\ University College Cork
}

Follow this and additional works at: https://arrow.tudublin.ie/aaschsslarts

Part of the Sociology Commons

\section{Recommended Citation}

Jawad, Rana \& Dolan, Paddy \& Skillington, Tracey. (2017). Sociology in the 21st Century: Reminiscence and Redefinition. Sociology. 51. 904-914. 10.1177/0038038515617685.

This Article is brought to you for free and open access by the Social Sciences at ARROW@TU Dublin. It has been accepted for inclusion in Articles by an authorized administrator of ARROW@TU Dublin. For more information, please contact arrow.admin@tudublin.ie, aisling.coyne@tudublin.ie,gerard.connolly@tudublin.ie.

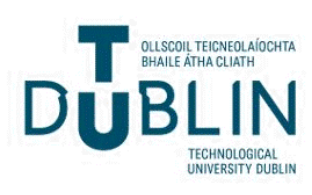


See discussions, stats, and author profiles for this publication at: https://www.researchgate.net/publication/299345299

\section{Sociology in the 21st Century: Reminiscence and Redefinition}

Article in Sociology · August 2017

DOI: $10.1177 / 0038038515617685$

\section{CITATIONS}

3 authors:

Rana Jawad

University of Bath

43 PUBLICATIONS 457 CITATIONS

SEE PROFILE

= 8 Tracey Skillington

University College Cork

42 PUBLICATIONS 167 CITATIONS

SEE PROFILE

Some of the authors of this publication are also working on these related projects:

Norbert Elias's unpublished works on sports, leisure, culture View project

Project Sport and nationalism View project
READS

4,661

Paddy Dolan

Technological University Dublin - City Campus 68 PUBLICATIONS 633 CITATIONS

SEE PROFILE 


\section{Sociology in the 2 I st Century: Reminiscence and Redefinition}

\section{Rana Jawad}

University of Bath, UK

\section{Paddy Dolan}

Dublin Institute of Technology, Ireland

\section{Tracey Skillington}

University College Cork, Ireland

\section{Keywords}

boundaries, complexity, interdisciplinarity

\section{Introduction to the E-Special}

To celebrate the 50th anniversary of Sociology, the editorial board decided to produce four e-special issues reflecting the contributions of the journal across the decades. Each of the four e-specials focuses on a different theme: '1967-1979 Sociology and Social Class' edited by Ryan and Maxwell; 'Self-Identity and Its Discontents: Sociology in the 1990s' edited by Skinner, May and Rollock; 'Sociology in the 1980s: The Rise of Gender (and Intersectionality)' edited by Roth and Dashper; and 'Sociology in the 21st Century: Redefinition and Reminiscence' edited by Jawad, Dolan and Skillington.

The purpose of this e-special was to assess new developments in the research agenda of sociology as reflected through publications in Sociology during the period 2000-13. Two articles that featured in the journal before this time interval were also included on account of their seminal importance to new directions in sociological thinking. One theme, in particular, seemed to capture the essence of sociology's new spirit of

\section{Corresponding author:}

Rana Jawad, Department of Social and Policy Sciences, University of Bath, Claverton Bath, Bath BA2 7AY, UK.

Email: R.Jawad@bath.ac.uk 
adventure during this timeframe, that of boundary distinctions (those of a disciplinary as much as a social, cultural or political kind). Although the concern for boundaries has had a long history in sociological discourse during these years, sociology made a noticeably ardent attempt to push the boundaries of its discipline outwards to new frontiers of research in areas as diverse as climate change, genetic science, the knowledge economy, digital futures and changing patterns of migration. As it did so, it found itself confronted with certain predicaments such as how to maintain a distinctly sociological approach to an expanding range of social issues and, at the same time, preserve a level of relevance and appeal that transcends specific disciplinary boundaries. The quandaries sociology now faced proved conspicuously similar to those confronting society more generally. Indeed, the central problem by this period had become the determination of boundaries - boundaries of identity, subject relevance and belonging. Sociology would now respond to the dynamics of social change by adapting its conceptual and analytical frameworks to reflect the distinctive qualities of today's societies, but in a way that also preserves the contemporary relevance of its enduring traditions of thought.

The articles collected for this special issue, arguably, capture something of this new mood of adventure in sociological research, an eagerness to explore the limits to conventional categorical distinctions (e.g. between nature and society, violence and law, technology and society, the sovereign state and the global community of humanity), as well as the potentialities created by the new. Together, they offer important insights into how the sociological imagination is being creatively redefined by a new generation of sociologists.

\section{Disciplinary Boundaries - Sociology's Deference and Confidence}

One of the older articles included in this e-special is actually two linked articles by Norbert Elias, published in 1971 (Elias, 1971a, 1971b). The manuscript was apparently submitted and intended for publication as one complete article, but the journal editors considered it too long (Kilminster and Mennell, 2009). Indeed it has recently been republished as a single chapter to reflect this original purpose (Elias, 2009). For our purposes the main boundary that Elias addresses is that between sociology and philosophy, and, according to Elias, the unjustified deference that sociologists pay to philosophers. This relates mainly to questions of epistemology and the sociology of knowledge and ideology. Elias notes that when sociologists of knowledge are concerned with the status of their own knowledge claims they tend to seek validation through various philosophical pronouncements and principles. The articles remain relevant, and indeed fresh, even today due to the continued implicit, if not always explicit, self-relegation of sociology as a discipline in relation to philosophy. In terms of boundaries, Elias is asking not that the boundary between sociology and philosophy become more strictly policed, but that sociologists as a disciplinary community should expand beyond their self-inflicted limitations and claim their right to develop principles and standards of knowledge growth and advancement for their discipline. 
In the first article (part one), Elias argues that sociologists of knowledge focused almost exclusively on knowledge as ideology. He challenges the dualism of base and superstructure inherent in Marx's approach, situating this idea within the rising power chances of industrial entrepreneurs who demanded (and largely received) both state avoidance of economic concerns, and at times state promotion of their interests. This supposed 'autonomy' of the economy, as an aspect of the liberal ideology, was largely accepted by Marx, though 'infused with negative values' (1971a: 152). The rise of 'the economy' and economics (increasingly split from political economy) intertwined with the rise of an entrepreneurial class. The outcome for the social scientific understanding of the world was fragmentation and greater academic specialisation, a scenario that echoes through our times with repeated calls for breaking down false barriers in order to recognise the interdependence of many processes - social, cultural, economic and natural. Though Marx and other social scientists of the late 19th and early 20th centuries often worked within the perspective of identifying the structure of long-term social changes, Elias contends that this has been largely abandoned by contemporary sociologists. They have increasingly accepted the historians' assumptions of the unstructured nature of change. This too is an outcome of functional specialisation within the social sciences and humanities.

Ultimately Elias argues that the central problem with philosophies of knowledge is the avoidance of issues of historical change. The problem of knowing is reduced to the isolated, single subject in relation to a material world. This dualistic opposition produces philosophical advocates at either side of the divide, but ignores the intergenerational transmission and development of knowledge over centuries. This is a sociological problem for Elias, not one that philosophy as then constructed can solve. Sciences advance to the extent that they generate 'object-adequate' knowledge of structures and processes, largely irrespective of the wishes and concerns of the scientists themselves (though this is always a relative balance, as people cannot become completely detached from their practices).

\section{Substantive Boundaries - the Nature of the Social and the Natural}

While the boundary between sociology and philosophy remains porous and somewhat deferential, there is perhaps less unquestioned acceptance of philosophy's elevated status about the social sciences than in the 1970s. The direction of influence is still largely oneway traffic, and the tendency for sociologists to seek inspiration or new ideas from philosophical sources remains, but the epistemological hold over the discipline seems to have loosened. However, sociology's boundaries with the 'natural' sciences have become more blurred, with the rise of actor-network theory and the extension of 'the social' to material things. Science and technology studies have blurred borders between social and natural, or between society and nature. This has emerged in the context of the threat of climate change and other environmental threats to humanity (or more accurately, humanity's threat to other species and organisms), but also in the growing confidence of biologists in developing knowledge apparently relevant to the understanding of social action, as well as potentially useable by certain interested organisations keen to predict risk. 
These issues arise in Kerr and Cunningham-Burley's (2000) article which engages with the changing nature of reflexive modernity as a result of advances in the science, technology and institutions of the new human genetics. They note that the new challenges in this field, and the public's responses to them, reflect various tensions between reflexivity and objectivity, doubt and certainty, choice and coercion and between change and convention. They further argue that the new human genetics gives a false sense of choice and freedom since its main purpose is to further the purposes of clinical surveillance and medical certitude. Members of the public seeking to make use of new human genetics services are in fact constrained and unable to support more reflexive forms of modernity. In addition, professionals are more concerned with protecting their professional authority and dismiss the public as ignorant, thereby facilitating the expansion of a more commercial or privatised eugenics. However, it may be argued that theories of reflexive modernity are not purely abstract in nature - hence, Kerr and Cunningham-Burley (2000) note that sociological critique of the new human genetics is itself part of the process of reflexive modernisation. Thus, there is a need or a possibility for sociologists, scientists and policy-makers with a critical perspective on the new human genetics to form alliances to advocate for better regulation of genetic research and more earnest consideration of the responsibilities and interests of professionals. Even lay involvement in decision making from the public should be promoted since the main contribution of social science experts would be to combine theoretical and empirical insights in order to democratise the decision-making process and knowledge base around the new genetic science.

Additional insights to the dynamic disciplinary nature of sociology are provided by McLennan (2003) who argues that the rise of interest in chaos and 'complexity' theories must not be taken to mean that sociology is a rigid or over-simplified discipline. McLennan (2003) cites Andrew Sayer and Immanuel Wallerstein in order to critique the apparent disciplinary impasse of sociology between cultural relativism and scientific determinism. To the contrary, McLennan argues that the intrinsic feature of sociology is to expand its scope of enquiry constantly and not give in to institutional or empirical limitations like social policy has for example. Thus, McLennan advances an understanding of sociology which is transdisciplinary: it is a discipline with innately porous borders. This applies also to the question of research methods in that no social science discipline can claim a distinctive research method and, in fact, the explosion of types of data is now threatening the viability of sociological evidence.

These ideas are also echoed in Cooper's (2013) discussion of interdisciplinarity and the challenges this poses to sociology. Cooper (2013: 82, citing Bernstein) reminds us that sociology itself does 'not have a unitary or clearly bounded structure and that, unlike hierarchical knowledge structures, it lacks any integrating codes that could provide for the development of general theory'. Thus, it can be argued that sociology's own structure, the fact that it is already in some respects inherently interdisciplinary (Cooper, 2013), has particular practical significance for collaboration with other disciplines, and even that its structure helps place it in an awkward position in relation to new forms of academic governance. Cooper (2013) highlights the strong links between interdisciplinarity and the 'practical concerns' of governance, which therefore make concerns with 
problem solving prominent. We may query however, the extent to which public sociology is immune to the interdisciplinary and empiricist turn that Cooper expresses concerns about.

Issues of boundary maintenance or dissolution are also addressed in Murdoch's (2001) article on 'ecologising sociology'. This relates to the need of sociologists to move beyond any straightforward split between nature and society. This is due to the reciprocal influence between people and natural processes. Murdoch suggests that the actor-network theory (ANT) perspective developed by Bruno Latour and Michel Callon, among others, offers potential to move beyond dualistic thinking in environmental sociology. As is well known, ANT seeks to distribute agency across multiple actors within any network, including non-human actants, such as other animals and indeed things like technological devices. The assumed separation between human and non-human found in other sociological approaches is largely abandoned. The natural and the social are seen as co-constructed through their reciprocal relations. For Murdoch, future sociological work on environmental or ecological concerns would need to deal with hybrid 'nature-cultures'. He notes the objections of Bloor to ANT on the basis that it removes the perspective of the knowing subject. Here again we see an example of the assumed philosophical principle of the isolated, singular subject identified by Elias entering social scientific disputes. Murdoch argues that this merely sustains the dualistic boundary between nature and society, but concludes that Hacking's critique of ANT has more validity, suggesting as he does that the human capacity for language and reflection means some distinction must be made between human and non-human.

In a more recent article, Stevens (2012) also argues for the dissolution of perceived false boundaries between the social and natural, and claims that new approaches developed in ecopsychology could inform an emergent ecosociology. Though Stevens writes as a psychologist, he argues for a synthesis of psychological and sociological perspectives in order to apprehend direct experience and embodiment within a flowing, global context. He supports Catton and Dunlap's argument for a New Ecological Paradigm (NEP) in order to challenge the notion of human exemptionalism. In effect, this challenges long-held assumptions of boundaries between the human and non-human, and Stevens calls for extending the understanding of 'the social' to include non-human species and indeed material things of social and emotional significance. This is indeed a challenging prospect, as sociologists may perhaps need to become proficient in the language and theories of biologists, physicists and other 'natural' scientists in order to develop new syntheses. Stevens does not directly address this, but clearly reversing decades of academic functional specialisation would be fraught with conceptual difficulties, demanding investments in time and patience ill-suited to the contemporary short-termist demands on sociologists. Stevens argues for an ecosystem approach in order to understand human 'influence' on the environment; indeed, once humans are seen as integral to the whole ecosystem the concept of 'influence' is misplaced given that human properties and capacities have evolved within such systems. As Stevens argues, not only does disciplinary boundary maintenance mitigate against theoretical advances in this substantive area, but the cultural separation of nature and society has very real consequences for both. 


\section{Group Boundaries - 'Us' and 'Them'}

In terms of redefining the project of sociology, a clear theme develops in the 21 st century, though there are of course recurrent signs of emergence before this. As is well known, for much of the 20th century the implicit, if not always explicit, object of sociological inquiry has been the nation state, almost as if it represented an obvious self-contained unit. In an increasingly interdependent world such a limited perspective has become more and more untenable, notwithstanding the fact that there have been global processes of human migration, as an example, long before nation states even existed. However, once the European states in particular developed into a post-Westphalian consensus of imagined national sovereignties, sociologists working within these social units had largely accepted their parameters. But pollutants know no national borders, and so we all now live in a global risk society, to use Beck's phrase. Interdependent processes and conflicts have also contributed to the movement of people, involving various degrees of force and compulsion, which has generated new social tensions as 'outsiders' bring different religions, values and customs. The imagined cultural unity of the nation state, propagated through national educational processes and reinforced and amplified by mass media competing for public attention, tends to obscure the very cultural hybridity of the development of nation states in the first instance. Depending on how people are positioned within global networks, experiences range from resentment and status anxiety to excitement and concern across wider and wider geographic spaces. These are clearly uneven and often contradictory processes.

The question of human rights is central in the boundary between 'us' and 'them'. As people, irrespective of national, ethnic or religious affiliation or identification, are accorded the same universal rights, the significance of national citizenship potentially lessens. One's rights would no longer be guaranteed only by a national state, and only by virtue of membership in that national group, but also by supranational entities and organisations. And so another one of our 'out of time' selections includes a seminal article by another leading sociologist, Bryan Turner. In his 1993 article, Turner questions the ongoing practical relevance of a social theory that consistently fails to recognise the various ways in which human rights have moved steadily into a 'historical stage beyond citizenship' (1993: 498) in the post-Second World War era and perhaps, relatedly, also fails to offer any kind of adequate account of the rational potentials embedded in human rights, potentials that incidentally have informed the core conceptual framework of numerous struggles for democratic freedom since the 18th century.

Turner sets about trying to explain this blind spot in social theoretical reasoning before turning his attention to what he believes to be the central element accounting for the endurance of a human rights regime - its intricate connection to, and recognition of, our human vulnerability. The openness of the human body to 'wounding' as a consequence of the violence of deprivation, persecution, incarceration, discrimination and exclusion, for instance in combination with the increasingly self-destructive nature of the institutional order humanity creates to protect itself from harm, only intensify human vulnerability to suffering and, simultaneously, the need for a normatively grounded human rights regime. A significant body of sociological research has been conducted in the years since, exploring many of Turner's key insights on human vulnerability (e.g. 
Coeckelbergh, 2013; Verschraegen, 2009). Others have challenged many of its core analytical components, for instance, on the spectatorship of suffering and social practices of denial (Chouliaraki, 2013; Seu, 2010). Similarly, assumptions regarding the 'precariousness' of institutions (e.g. law and administration) in terms of their capacity to offer adequate protection to the vulnerable in society, have been disputed by those who point to the way legal protection is experienced differently, depending on one's status (e.g. citizen, non-citizen, in combination with other variables including ethnicity, class, gender, etc.). Bureaucratic failure to protect the most vulnerable too often stems from unequal treatment before the law and human rights stratification (see Morris, 2006). Morris, and indeed Hynes et al. (2011), call for a move towards a more inter-subjectively grounded sociology of human rights, one that is centrally concerned with the study of human rights discourse in practice.

Just as Turner problematised an unreflexive equation of human rights with citizenship rights, Susan Walby (2003: 532) calls attention to another misconception apparent in much of sociological reasoning - the tendency to assume with instinctive certainty that a neat correspondence prevails between nations, states, territories and polities, when everywhere 'the complex conflictual intertwining' of multiple sites of authority means that the political and the sovereign are rarely perfectly congruent. Walby alludes to several examples, including the Irish and Basque nations, as a point of illustration, and calls on the sociological imagination to capture this more differentiated political landscape. Sociology, Walby adds, cannot exclude a priori what can be observed empirically, that is, multiple models of political organisation, as well as the steady movement more generally towards the transnationalisation of legal, economic and political decision-making authority (e.g. the Single European Market and international law). What Walby advocates in response to these developments is an interpretive framework that does not abandon sociological heritage per se, but does work towards sharpening sociological understandings of how societies engage continuously in processes of communication and adaptation to change both within the confines of singular states, nations and polities, as well as across multiple interconnected settings. For Walby, the central task for sociology, therefore, is to open up theoretically, empirically and methodologically to the new reflexive imperative and optimise its abilities to capture the emerging dynamic of change and stability, as well as the shifting boundaries between the political inside/ outside. In large part, such debates are also reflected in the sociology of religion which regained new life in the 2000s as can be seen in Voas and Crockett (2005) - not included formally in this special issue.

Also offering a rich sociological exploration of the interdependencies that emerge between global, national and localised mechanisms of change is Kate Nash (2009). Here the author focuses specifically on how international law, as it is administered through state policy, constructs different categories of citizen ranging from full citizens, marginal, quasi (e.g. political refugees), sub-citizens (asylum seekers, detainees) and 'uncitizens' (illegal migrants). Processes of globalisation have undoubtedly extended the radius of human rights and issues of justice beyond the confines of individual states, but whether this is actually contributing to a more cosmopolitan justice by equalising the distribution of rights among citizens and non-citizens alike is another matter. Sociological investigations of the context in which human rights are actualised reveal a far more nuanced 
picture. Legal entitlement is but one essential element of the enjoyment of rights. Rights must also be actualised at the administrative, social and political levels. It is at these levels that Nash detects a 'complication' in 'the right to have rights' and the formation of new varieties of inequality between citizens and non- or quasi-citizens.

Nash (2009) offers a rich sociological exploration of how the cosmopolitanisation of law does not necessarily lead to greater equality before the law, but frequently gives rise to a new stratified and highly unequal rights regime where the level of legal protection enjoyed by the individual is determined by which category of citizenship they fall into. At the same time, as this order of difference and inequality prevails, campaigners draw on the same international human rights norms to contest how states misframe ideals of justice and equality. The challenge for sociology, therefore, is to assess how universalisms frequently implode under the weight of state administrative practices, but in so doing, also inspire new campaigns for democratic reform. Inequality thus continues to prove itself an important stimulus to action and societal learning in the name of human rights.

Beck (2011) takes up these ideas on cosmopolitanism further in a conference paper which we include here due to the significant issues it raises. In this presentation, Beck (2011: 7) argues that class is no longer an adequate sociological category to capture 'the cosmopolitan challenge at the beginning of the 21 st century', in large part due to its close association with the category of nation state which itself has become less salient. In addition, there are more transnational social inequalities that are reflected in bodies, families and working lives of nations which sociology and the social sciences more generally need to consider. Beck (2011) advocates for a paradigm shift from 'methodological nationalism' to 'methodological cosmopolitanism' which reflects deep interconnectedness in modern social identities. This is more than just about how human beings and relationships are linked, but rather how the dichotomy between the poor and rich nations, 'them' and 'us', is mutually constituted and mutually exclusive. Beck (2011) thus calls for new categories that also move beyond the distinction of North and South which would capture the changed nature of economic and social inequalities in the globalised era.

Castles (2003) raises similar concerns in his article on the issue of forced migration. Here Castles considers the most likely triggers causing the number of global refugees, asylum seekers, internally displaced and trafficked individuals to soar (a total of 51.2 million in 2013, see UNHCR Global Trends, 2014) including new sources of political instability, economic crisis and resource deprivation. The author points to the role played by global capitalist interests in exacerbating existing tensions and maintaining unequal trade and investment arrangements. Economically, politically and environmentally, the challenges facing the developing world today are shaped to a significant extent by the actions of the Global North. In preserving an international economic and political order that reinforces underdevelopment and intensifies conflict over diminishing reserves of essential resources, including arable lands, water and food sources, more powerful states and the corporate interests they represent do more to increase forced migration than alleviate it. On the basis of these evaluations, Castles calls for a rigorous sociological analysis of forced migration as a 'societal totality', that is, as both a lived reality for increasing numbers and as a phenomenon triggered by political and economic forces operative at the local, national and international level. The aim is 
to cultivate a type of multi-levelled sociological perspective on the meta-problematic of forced migration, also advocated more generally by Beck. This perspective shows how forced migration is produced by the combined effect of several processes of societalisation (including large scale natural resource acquisition, war, poverty, loss of entitlement to essential food and water sources, etc.).

Urry (2002) also addresses the increasing intensity of movements of people across space, and the loss of social capital and connection that people face when such spatial mobility is restricted. Urry's article is more directly related to the crossing of spatial, virtual and imaginary boundaries, and how these dimensions are linked. He sees physical co-presence remaining essential for building trust and maintaining social relationships. Thus, cyberspace interactions and new technologies of communication and self-presentation are becoming increasingly intertwined and interdependent. Intermittent and occasional physical co-presence is often required to maintain and develop social networks across spaces. So, unlike Putnam, Urry sees social capital as increasingly dependent upon one's ability to engage in such mobilities. Denying access to physical mobility reduces the chances of social mobility and exacerbates social exclusion. As societies become more globalised, our need for occasional physical co-presence also stretches across our personal networks encompassing the planet. Though Urry (2002: 264) does not address this specifically in this article, this 'globalisation of intermittent co-presence' will have profound consequences for ecological sustainability.

\section{Temporal Boundaries - into the Future}

The work of Walby, Nash, Turner, Beck, Castles and Urry gives us some indication of how sociology continues to cultivate its theory-based analytic capacities and methodological perspectives across a range of relevant issues today. While each examines the dynamic of social change in terms of a new unfolding global present, Halford, Pope and Weal's (2013) article 'Digital futures? Sociological challenges and opportunities in the emergent semantic web' offers us insights on the future potentials of new web search tools and the type of cognitive frontiers foreseen by the coming era of 'open data'. The latter is said to hold out enormous potential for the sociology communities of the future in terms of understanding the type of interconnections that we can only hint at today (e.g. shifts in patterns of social behaviour, migration flows, employment trends across sectors, regions, generations, poverty, consumption, etc.). The authors challenge the sociology community to carry this project of learning forward and become active in the shaping of new, 'not yet' moments in digital sociological research tool design. Sociology must begin to engage more with unfolding digital potentialities to ensure that the sociological imagination is always reaching forward to new visions of the good society as the continuation of the 'old' (in terms of the traditions of the discipline) and its transfiguration.

\section{Conclusion}

Identifying key trends and promising articles for this e-special has been a difficult though fascinating task. While our starting point was the disciplinary boundary surrounding sociology, it quickly became clear that other boundary distinctions were also highly 
relevant, such as those between different nations, communities, time periods and between the social and the natural. Sociology's boundaries will no doubt continue to change and blur so long as its objects of inquiry continue to be actions and dependencies between people, and the relatively autonomous ideas, ideologies, emotions and values to which these interactions and interdependences relate. As these change, so too does the discipline. In the early 1970s, Elias made a strong, confident defence of sociology, asserting its autonomy and strengths over the discipline of philosophy. McLennan, much later, would also defend sociology against charges of lacking complexity, of being mired in the static language of structure, and being beholden to outmoded notions of linearity and determinism. The articles presented in this e-special remind us of sociology's ongoing capacities to explain the social without resorting to the fatalism of imagined inexplicable randomness and fluidity. One could argue that sociology's task for the future is even more formidable as social tensions and inequalities continue to expand globally. Making self-imposed boundaries more visible perhaps enables us to reimagine the continuities and connections that bind societies across space and time.

\section{Funding}

This research received no specific grant from any funding agency in the public, commercial or not-for-profit sectors.

\section{References}

Chouliaraki L (2013) The Ironic Spectator: Solidarity in the Age of Post-Humanitarianism. Cambridge: Polity Press.

Coeckelbergh M (2013) Human Being @ Risk: Enhancement, Technology and the Evaluation of Vulnerability. New York: Springer.

Elias N (2009) Sociology of knowledge: New perspectives. In: Elias N Essays I: On the Sociology of Knowledge and the Sciences. Dublin: University College Dublin Press, 3-41.

Hynes P, Lamb M, Short D, et al. (eds) (2011) Sociology and Human Rights: New Engagements. Oxon: Routledge.

Kilminster R and Mennell S (2009) Note on the text. In: Elias N Essays I: On the Sociology of Knowledge and the Sciences. Dublin: University College Dublin Press, ix-xxvii.

Morris L (2006) Sociology and rights - an emergent field. In: Morris L (ed.) Rights: Sociological Perspectives. London: Routledge, 1-16.

Seu IB (2010) 'Doing denial': Audience reaction to human rights appeals. Discourse \& Society 21(4): 438-457.

UNHCR (United Nations High Commissioner for Human Rights) Global Trends 2014: World at War. Available at: http://unhcr.org/556725e69.html (accessed 5 September 2015).

Verschraegen G (2009) Violence and vulnerability. International Sociology 24(2): 216-220.

Voas D and Crockett A (2005) Religion in Britain: Neither believing nor belonging. Sociology 39(1): 11-28.

Rana Jawad is Senior Lecturer in Social Policy at the Department of Social and Policy Sciences, University of Bath. Rana's main research interests are in studying the social policies and the welfare systems of the Middle East and North Africa region, with a particular sub-interest in the role of religiously based social welfare action that also focuses on the UK. She draws from a wide range 
of disciplines in her research in an attempt to understand foundational questions related to social action, policy making, institutional development, social justice and well-being. She is founder and convener of the MENA social policy network; is a member of the editorial board of Sociology and co-convener of the Social Policy Association's International and Comparative Social Policy Working Group. She is the author of Social Welfare and Religion in the Middle East: A Lebanese Perspective (The Policy Press, 2009) and Faith-Based Welfare and Religion: From Wellbeing to Ways of Being (The Policy Press, 2012).

Paddy Dolan is a lecturer in Consumer Research at Dublin Institute of Technology. He is a sociologist whose research interests include figurational theory, consumer culture, sport, organisational change, cosmopolitanism and childhood.

Tracey Skillington is a lecturer in the Department of Sociology, University College Cork. Her research interests include the sociology of human rights, sovereignty and its transformation, global justice, borders, cosmopolitanism, collective memory and identities. She recently guest edited a special issue of the European Journal of Social Theory (August 2015 18(3)) entitled 'Perspectives on climate change'. Other recent publications include (2013) 'UN genocide commemoration: Transnational scenes of mourning and the global project of learning from atrocity', British Journal of Sociology 64(3) and (2012) 'Climate change and the human rights challenge: Extending justice beyond the borders of the nation state', International Journal of Human Rights 16(8). Her monograph entitled Climate Justice and Human Rights (Palgrave Macmillan) is forthcoming.

Date submitted September 2015

Date accepted September 2015 